\title{
Diagnostic accuracy of the Finnish Diabetes Risk Score for the prediction of undiagnosed type 2 diabetes, prediabetes, and metabolic syndrome in the Lebanese University
}

\author{
Maher Abdallah ${ }^{1 *}$, Safa Sharbaji ${ }^{2}$, Marwa Sharbaji ${ }^{2}$, Zeina Daher ${ }^{1}$, Tarek Faour ${ }^{3}$, Zeinab Mansour ${ }^{3}$ \\ and Mohammad Hneino ${ }^{4}$
}

\begin{abstract}
Background: Risk scores were mainly proved to predict undiagnosed type 2 diabetes mellitus (UT2DM) in a noninvasive manner and to guide earlier clinical treatment. The objective of the present study was to assess the performance of the Finnish Diabetes Risk Score (FINDRISC) for detecting three outcomes: UT2DM, prediabetes, and the metabolic syndrome (MS).

Methods: This was a prospective, cross-sectional study during which employees aged between 30 and 64, with no known diabetes and working within the faculties of the Lebanese University (LU) were conveniently recruited. Participants completed the FINDRISC questionnaire and their glucose levels were examined using both fasting blood glucose (FBG) and oral glucose tolerance tests (OGTT). Furthermore, they underwent lipid profile tests with anthropometry.

Results: Of 713 subjects, 397 subjects (55.2\% female; $44.8 \%$ male) completed the blood tests and thus were considered as the sample population. $7.6 \%$ had UT2DM, 22.9\% prediabetes and 35.8\% had MS, where men had higher prevalence than women for these 3 outcomes $(P=0.001, P=0.003$ and $P=0.001)$ respectively. The AUROC value with 95\% Confidence Interval (Cl) for detecting UT2DM was 0.795 (0.822 in men and 0.725 in women), 0.621 (0.648 in men and 0.59 in women) for prediabetes and 0.710 ( 0.734 in men and 0.705 in women) for MS. The correspondent optimal cut-off point for UT2DM was 11.5 (sensitivity $=83.3 \%$ and specificity $=61.3 \%$ ), 9.5 for prediabetes (sensitivity $=73.6 \%$ and specificity $=43.1 \%$ ) and 10.5 (sensitivity $=69.7 \%$; specificity $=56.5 \%)$ for MS.

Conclusion: The FINDRISC can be considered a simple, quick, inexpensive, and non-invasive instrument to use in a Lebanese community of working people who are unaware of their health status and who usually report being extremely busy because of their daily hectic work for the screening of UT2DM and MS. However, it poorly screens for prediabetes in this context.
\end{abstract}

Keywords: AUROC, Cutoff, FBG, FINDRISC, MS, OGTT, Prediabetes, Screening, UT2DM, WC

*Correspondence: Maher.abdallah@ul.edu.lb

1 Faculty of Public Health, Lebanese University, Hadat, Beirut, Lebanon

Full list of author information is available at the end of the article

\section{Background}

Diabetes mellitus (DM) is a chronic metabolic disorder characterized by persistent hyperglycemia [1]. It is preceded by an asymptomatic state known as prediabetes which might begin 12 years before the diagnosis, although glucose values seemed to be tightly regulated

c) The Author(s) 2020. This article is licensed under a Creative Commons Attribution 4.0 International License, which permits use, sharing, adaptation, distribution and reproduction in any medium or format, as long as you give appropriate credit to the original author(s) and the source, provide a link to the Creative Commons licence, and indicate if changes were made. The images or other third party material in this article are included in the article's Creative Commons licence, unless indicated otherwise in a credit line to the material. If material is not included in the article's Creative Commons licence and your intended use is not permitted by statutory regulation or exceeds the permitted use, you will need to obtain permission directly from the copyright holder. To view a copy of this licence, visit http://creativecommons.org/licenses/by/4.0/. The Creative Commons Public Domain Dedication waiver (http://creativecommons.org/publicdomain/zero/1.0/) applies to the data made available in this article, unless otherwise stated in a credit line to the data. 
within the normal range until 2-6 years before the clinical diagnosis when a sharp increase was detected [2]. In fact, during this stage insulin resistance occurs and triggers damage to several organs, such as eyes, kidneys, blood vessels, and the heart [3]. Furthermore, insulin resistance is associated with hyperinsulinemia which is the underlying cause of the MS and, once acquired, those with a genetic predisposition would develop the other features of the disorder including hypertension, hypertriglyceridemia, low high-density lipoprotein cholesterol (HDL-C), and the development of type 2 diabetes (T2D) [4].

The prevalence of diabetes, prediabetes, and MS is increasing rapidly worldwide $[5,6]$. According to the international diabetes federation (IDF), approximately 38.7 million people or $9.6 \%$ of adults aged $20-79$ years suffer from diabetes which will likely double in 2045 and about $49.1 \%$ of these are undiagnosed in the IDFthe Middle East North Africa region (MENA) [7]. In Lebanon, the prevalence of diabetes was $14 \%$ in 2017 compared to $12.6 \%$ according to the World Health Organization (WHO) in 2016 [8]. Similarly, the prevalence of diabetes and prediabetes was found to be $15 \%$ and $40.3 \%$ respectively in the Greater Beirut Area in 2017 [9]. Retinopathy, heart disease, and neuropathy have been the most highly correlated complications with diabetes among the Lebanese population and impose a serious economic burden on the healthcare system $[10,11]$. Moreover, the prevalence of MS in the Middle East countries was estimated to be $25 \%$ in 2017[12]. Interestingly, Prediabetes and diabetes were both positively correlated with the different components of the MS within the Lebanese population [11].

Given all these pieces of evidence, early detection and treatment of prediabetes, diabetes, and MS would delay progression to diabetes as well as its relevant health and economic burdens $[3,7,13]$. Indeed, a two-step strategy could be efficient and highly recommended by many guidelines [14, 15]. First, rapid preliminary screening is performed to identify high-risk individuals using risk assessment tools. Secondly, they must be referred for routine blood measures for a final definitive diagnosis.

Till now, several risk assessment tools have been developed for initial screening. However, many of them are not widely accepted and practically used since they may require invasive and expensive blood testing such as the Atherosclerosis Risk in Communities score (ARIC) and the Framingham Offspring score [2, 15]. In contrast, there are also non-invasive risk scores that rely only on self-reported data. The well-known ones are the ADA risk score [16], the German Diabetes Risk Score (GDRS) [17], and the Finnish Diabetes Risk Score (FINDRISC). The latter has been most frequently tested for detecting diabetes risk [7, 18]. However, few studies examined its ability to predict MS. Besides, as an external validation must be done in the population in which they are intended to be used $[15,19]$ we aimed to evaluate the performance of the FINDRISC in detecting UT2DM, prediabetes, and MS in a Lebanese community.

\section{Methods}

\section{Study design and participants}

This was a prospective, cross-sectional study, conducted between January 2018 and May 2019 over two phases. During the first phase, the staffs working within the faculties of the LU (Office workers, instructors, and cleansers), aged older than 30 to 64 years and who accept to submit the inform consent were recruited by convenience sampling from the campuses of the LU across four regions in Lebanon (Beirut, Bekaa, South, and North) and filled the FINDRISC questionnaire. However, individuals who reported having diabetes, women who reported to be pregnant, and people with any physical disability that prevents anthropometric measurements were excluded. In the second phase, faculties were contacted in advance by phone for a blood test analysis appointment.

\section{Measurements \\ Questionnaire}

FINDRISC was originally used as a prediction tool to identify patients at risk of developing diabetes over next 10 years [20]. It consists of eight, self-reported questions related to age, Body mass index (BMI), physical activity, vegetable and fruit intake, medical treatment of hypertension, history of hyperglycemia and, diabetes family history. A rating score between 0 and 14 points indicates a low to moderate risk of diabetes; a risk score between 15 and 20 points indicates a high risk of diabetes and a rating score of more than 20 points indicates a very high risk of diabetes. After signing the informed consent, all participants completed the questionnaire that included the original eight items of FINDRISC, with additional information addressing the socio-demographic data, smoking, and educational level.

\section{Anthropometrics}

Bodyweight and waist circumference (WC) were measured for each participant by Nutrition students [21]. Weight was measured to the nearest $0.1 \mathrm{~kg}$ on a calibrated digital scale, with light clothing and without shoes. Using a flexible measuring tape, WC was measured midway between the lowest rib and the iliac crest. However, the height was self-reported. Then, BMI was calculated by dividing body mass in kilograms by height in meters squared [22]. 


\section{Resting Blood Pressure}

Blood Pressure measurement was taken after the participant had been seated and relaxed for 5 min without any distractions, using an automatic monitor (Ross max monitoring, Swiss design) with appropriate cuff's size. Furthermore, the person's upper arm was put into the cuff loops, 1 or $2 \mathrm{~cm}$ above the elbow, then letting it comfortably rest on the table [23]. Those who had a blood pressure level higher than 120/80 $\mathrm{mmHg}$ upon measurement, were notified to seek medical advice.

\section{Laboratory measurements}

Participants were instructed to fast for at least $12 \mathrm{~h}$ and abstain from vigorous exercise in the evening and the morning of the investigation. They were also asked to abstain from caffeine and smoking on the morning of the visit. After ensuring that the fasting period was accomplished completely, the blood sampling procedure was explained by a trained laboratory technician. A total of 3-5 $\mathrm{ml}$ of fasting venous blood sample was collected in a serum clot activator tube and centrifuged at $4000 \mathrm{rpm}$ for $10 \mathrm{~min}$ on the same day, and then serum was transferred to another tube and stored at $-22{ }^{\circ} \mathrm{C}$ for biochemical examination. Following this, a load of $75 \mathrm{~g}$ of anhydrous glucose in a volume of $200 \mathrm{ml}$ was administered to each individual for the oral glucose tolerance test (OGTT) [14]. After two hours, a second blood sample was drawn to assess the glucose levels. Fasting blood glucose (FBG), triglycerides (TG), total cholesterol (TC), and high-density lipoprotein-cholesterol (HDL-C) levels were detected using a biochemical analyzer (Unicel DxC 600, Synchron Clinical System, BECKMAN COULTER, Cobas C111). However, lowdensity lipoprotein-cholesterol (LDL-C) level was calculated by the Freidwald formula (24), only if the total TG level did not exceed $300 \mathrm{mg} / \mathrm{dl}$. All these blood analysis procedures were conducted in certified laboratories located in each region (Lebanese University Medical Centre, Mount Lebanon; Hammoud hospital, South Lebanon; Libano Français Hospital, Bekaa and Tripoli Medical Center, North Lebanon). The results of the blood tests were provided to the participants.

\section{Outcomes}

We had three outcome variables of interest: UT2DM, Prediabetes, and MS.

Both UT2DM and Prediabetes were defined according to the latest American Diabetes Association (ADA) criteria [14].
- Individuals who had FBG level $\geq 126 \mathrm{mg} /$ dl $(7.0 \mathrm{mmol} / \mathrm{l})$ or 2-h blood glucose (2-h BG) $\geq 200 \mathrm{mg} / \mathrm{dl}(11.1 \mathrm{mmol} / \mathrm{l})$ were classified as UT2DM.

- Participants who had impaired fasting glucose (IFG) i.e. blood glucose (BG) $\geq 100 \quad(5.6 \mathrm{mmol} / \mathrm{l})$ and $<126 \mathrm{mg} / \mathrm{dl}(7.0 \mathrm{mmol} / \mathrm{l})$ or impaired glucose tolerance (IGT) i.e. $2 \mathrm{~h}$ blood glucose $(2 \mathrm{~h} \mathrm{BG}) \geq 140$ $(7.8 \mathrm{mmol} / \mathrm{l})$ and $<200 \mathrm{mg} / \mathrm{dl}(11.1 \mathrm{mmol} / \mathrm{l})$ were considered as prediabetics.

Whereas, MS was defined according to the latest National Cholesterol Education Program Adult treatment panel III (NCEP ATP III) diagnostic criteria (2005revision) [25]. At least three of the following criteria were present:

- Abdominal obesity (WC $\geq 102 \mathrm{~cm}$ in men and $\geq 88 \mathrm{~cm}$ in women)

- Hypertriglyceridemia ( $\mathrm{TG} \geq 150 \mathrm{mg} / \mathrm{dl}$ or $1.695 \mathrm{mmol} / \mathrm{l})$

- Low HDL-C $(\mathrm{HDL}<40 \mathrm{mg} / \mathrm{dl}$ in men and $<50 \mathrm{mg} / \mathrm{dl}$ in women)

- Elevated blood pressure (Systolic blood pressure $\mathrm{SBP}>130 \mathrm{mmHg}$ or Diastolic blood pressure $\mathrm{DBP}>85 \mathrm{mmHg}$ ) or the use of antihypertensive medication.

- Elevated blood glucose (FBG $\geq 100 \mathrm{mg} / \mathrm{dl})$.

\section{Statistical analyses}

Statistical analysis was conducted using SPSS (IBM Corp, SPSS Statistics version 23). Descriptive statistics of those who underwent blood tests were expressed as means ( \pm standard deviation) for continuous variables and as proportions for categorical variables. Differences in the socio-demographic $(\mathrm{SD})$ variables between genders were computed using an independent samples t-test for continuous variables and a Chi-square test for categorical variables, while between FINDRISC categories using a one-way ANOVA test for continuous variables and a Chi-square test for categorical variables. To evaluate the FINDRISC accuracy performance we calculated the area under the receiver operating curve (AUROC), sensitivity (the probability that the test is positive for subjects with type 2 diabetes), specificity (the probability that the test is negative for subjects without type 2 diabetes) with $95 \%$ CIs (95\% confidence intervals). To create the ROC curve, sensitivity was plotted on the $y$-axis, and the false-positive rate (1-specificity) was plotted on the $x$-axis. Then optimal cut-off points were determined by the point with the closest distance to $(0 ; 1)$ in the ROC curve which 
maximizes the sensitivity and specificity of the test (Tradeoff between sensitivity and specificity).

\section{Results}

\section{Participant characteristics}

Out of 713 individuals who were initially enrolled in the study and filled the questionnaire, 316 (44.3\%) did not follow the complete blood tests procedures; and therefore, the data of the remaining 397 were used for the validation of the FINDRISC. The sample was composed of 219 women (55.2\%) and 178 men (44.8\%). The mean age was $48.5( \pm 9)$ and there was no statistical significance between men and women in terms of age $(P=0.248)$. Men had higher BMI (28.5 vs. $26.3 ; P<0.001)$,
WC (102.8 vs. $90.5 ; P<0.001)$, were heavier smokers (172 vs. $137 ; P<0.001$ ) and were on BP medication more than women ( 35 vs. $28 ; P=0.042$ ). However, women had a stronger $1^{\text {st }}$ degree family history of T2DM (92 vs.76; $P=0.002$ ) and were relatively less physically active (21 vs. 38; $P=0.001)$. The mean values of the blood tests including FBG $(P<0.001)$, OGTT $(P<0.001)$, TG $(P<0.001)$, SBP $(P=0.001)$ and DBP $(P=0.003)$ were higher in men than in women, except for HDL-C $(P<0.001)$, LDL-C $(P=0.006)$ and TC $(P<0.001)$ (Table 1$)$.

\section{Prevalence of UT2DM, prediabetes, and MS}

30 (7.6\%) individuals had UT2DM, 91 (22.9\%) had prediabetes and 142 (35.8\%) had MS. In addition, Men had

Table 1 FINDRISC components and socio-demographic characteristics according to gender

\begin{tabular}{|c|c|c|c|c|}
\hline & \multirow{2}{*}{$\begin{array}{l}\text { Overall } \\
(\mathrm{N}=397)\end{array}$} & \multicolumn{2}{|l|}{ Gender } & \multirow[t]{2}{*}{$P$} \\
\hline & & $\begin{array}{l}\text { Men } \\
(n=178,44.8 \%)\end{array}$ & $\begin{array}{l}\text { Women } \\
(n=219,55.2 \%)\end{array}$ & \\
\hline \multicolumn{5}{|l|}{ FINDRISC components } \\
\hline Age (in years) & $48.4( \pm 9)$ & $49.06( \pm 9.6)$ & $48( \pm 8.4)$ & 0.248 \\
\hline \multicolumn{5}{|l|}{ Family Hx for T2DM } \\
\hline No family history & $169(42.6 \%)$ & $87(48.9 \%)$ & $82(37.4 \%)$ & $0.002^{*}$ \\
\hline $1^{\text {st }}$ degree relatives & $168(42.3 \%)$ & $76(42.7 \%)$ & $92(42 \%)$ & \\
\hline $2^{\text {nd }}$ degree relatives & $60(15.1 \%)$ & $15(8.4 \%)$ & $45(20.5 \%)$ & \\
\hline WC (in cm) & $96( \pm 14.3)$ & $102.8( \pm 12.1)$ & $90.5( \pm 13.6)$ & $0.000^{*}$ \\
\hline $\mathrm{PA} \geq 30 \mathrm{in} \mathrm{min} / \mathrm{day}$ & $59(14.9 \%)$ & $38(21.3 \%)$ & $21(9.6 \%)$ & $0.001^{*}$ \\
\hline Daily intake of F\&V & $227(57.3 \%)$ & $95(53.4 \%)$ & $132(60.6 \%)$ & 0.091 \\
\hline Use of BP medication & $63(15.9 \%)$ & $35(19.7 \%)$ & $28(12.8 \%)$ & $0.042^{*}$ \\
\hline Hx of high BG & $42(10.6 \%)$ & $24(13.5 \%)$ & $18(8.2 \%)$ & 0.063 \\
\hline BMI (in kg/m²) & $27.3( \pm 4.7)$ & $28.5( \pm 4.5)$ & $26.3( \pm 4.6)$ & $0.000^{*}$ \\
\hline \multicolumn{5}{|c|}{ Socio-demographic characteristics } \\
\hline Smoking & & & & $0.000^{*}$ \\
\hline Never & $225(56.7 \%)$ & $84(47.2 \%)$ & $141(64.4 \%)$ & \\
\hline Former & $17(4.3 \%)$ & $15(8.4 \%)$ & $2(0.9 \%)$ & \\
\hline Current & $309(43.3 \%)$ & $172(49.3 \%)$ & $137(37.6 \%)$ & \\
\hline \multicolumn{5}{|c|}{ Educational level (as degree) } \\
\hline Less than brevet & $48(12.1 \%)$ & $28(15.7 \%)$ & $20(9.1 \%)$ & 0.105 \\
\hline Brevet & $19(4.8 \%)$ & $11(6.2 \%)$ & $8(3.6 \%)$ & \\
\hline Baccalaureate & $70(17.6 \%)$ & $28(15.7 \%)$ & $42(19.2 \%)$ & \\
\hline Bachelor & $96(24.2 \%)$ & $36(20.2 \%)$ & $60(27.4 \%)$ & \\
\hline Master's and above & $164(41.3 \%)$ & $75(42.1 \%)$ & $89(40.6 \%)$ & \\
\hline \multicolumn{5}{|l|}{ Family income (in LBP) } \\
\hline$<1$ million & $38(9.6 \%)$ & $15(8.4 \%)$ & $23(10.5 \%)$ & $0.000^{*}$ \\
\hline 1 million-2 million & $74(18.6 \%)$ & $43(24.2 \%)$ & $31(14.2 \%)$ & \\
\hline 2 million-3 million & $114(28.7 \%)$ & 34 (19.1\%) & 80 (36.5\%) & \\
\hline$>3$ million & $171(43.1 \%)$ & $86(48.3 \%)$ & 85 (38.8\%) & \\
\hline
\end{tabular}

*Statistically significance

Data are presented as means $( \pm S D$ ) for continuous variables and as frequencies (percentage) for categorical variables. Hx history, T2DM type 2 diabetes mellitus, WC waist circumference, $P A$ physical activity, F\&V fruits and vegetables, BP blood pressure, $B G$ blood glucose, BMI body mass index, $L B P$ Lebanese pound 
Table 2 Blood tests and the three outcome variables according to gender

\begin{tabular}{|c|c|c|c|c|}
\hline & \multirow{2}{*}{$\begin{array}{l}\text { Overall } \\
(\mathrm{N}=397)\end{array}$} & \multicolumn{2}{|l|}{ Gender } & \multirow[t]{2}{*}{$P$} \\
\hline & & $\begin{array}{l}\text { Men } \\
(n=178,44.8 \%)\end{array}$ & $\begin{array}{l}\text { Women } \\
(n=219,55.2 \%)\end{array}$ & \\
\hline \multicolumn{5}{|l|}{ Blood tests } \\
\hline FBG (in mg/dl) & $96( \pm 30.3)$ & $102.70( \pm 41.639)$ & $91.53( \pm 14.325)$ & $0.000^{*}$ \\
\hline $2 \mathrm{~h}$ OGTT (in mg/dl) & $111( \pm 64.8)$ & $125.74( \pm 85.688)$ & $99.70( \pm 36.985)$ & $0.000^{*}$ \\
\hline TC (in mg/dl) & $198( \pm 41.2)$ & $189.71( \pm 42.258)$ & $205.20( \pm 39.196)$ & $0.000^{*}$ \\
\hline TG (in mg/dl) & $139( \pm 87.8)$ & $160.97( \pm 98.770)$ & $122.65( \pm 73.715)$ & $0.000^{*}$ \\
\hline $\mathrm{HDL}-\mathrm{C}$ (in mg/dl) & $48( \pm 13.6)$ & $41.56( \pm 11.083)$ & $54.04( \pm 12.954)$ & $0.000 *$ \\
\hline LDL-C (in mg/dl) & $123( \pm 36.9)$ & $117.39( \pm 39.656)$ & $127.71( \pm 33.955)$ & $0.006^{*}$ \\
\hline $\mathrm{SBP}$ (in mmHg) & $121( \pm 23.4)$ & $125.48( \pm 25.957)$ & $117.65( \pm 20.610)$ & $0.001^{*}$ \\
\hline DBP (in mmHg) & $77( \pm 15.3)$ & $80.29( \pm 17.013)$ & $75.49( \pm 13.547)$ & $0.003^{*}$ \\
\hline FINDRISC score & $10( \pm 4.2)$ & $11.07( \pm 4.685)$ & $10.79( \pm 3.958)$ & 0.528 \\
\hline \multicolumn{5}{|l|}{ Outcomes } \\
\hline UT2DM & $30(7.6 \%)$ & $22(12.4 \%)$ & $8(3.7 \%)$ & $0.001^{*}$ \\
\hline Prediabetes & 91 (22.9\%) & $53(29.8 \%)$ & $38(17.4 \%)$ & $0.003^{*}$ \\
\hline MS & $142(35.8 \%)$ & $85(47.7 \%)$ & $57(26 \%)$ & $0.000^{*}$ \\
\hline
\end{tabular}

*Statistical significance

FBG fasting blood glucose, 2 O OGTT 2 hours oral glucose tolerance test, $T C$ total cholesterol, $T G$ triglyceride, HDL-C high density lipoprotein cholesterol, $L D L-C$ low density lipoprotein cholesterol, SBP systolic blood pressure, DBP diastolic blood pressure, UTDM2 undiagnosed type 2 diabetes mellitus, MS metabolic syndrome

statistically higher prevalence of UT2DM $(P=0.001)$, prediabetes $(P=0.003)$ and MS $(P=0.001)$ (Table 2$)$. No clinical side effects were reported following the procedure of blood sampling.

\section{Diagnostic accuracy of FINDRISC in detecting UT2DM, prediabetes and MS \\ Diagnostic accuracy for UT2DM}

The AUROC curve for detecting UT2DM was 0.795 (95\% CI: 0.728-0.862) overall, with $0.822(0.749-0.895)$ for men better than, 0.725 (0.589-0.861) for women (Fig. 1). The correspondent optimal cutoff point was a FINDRISC

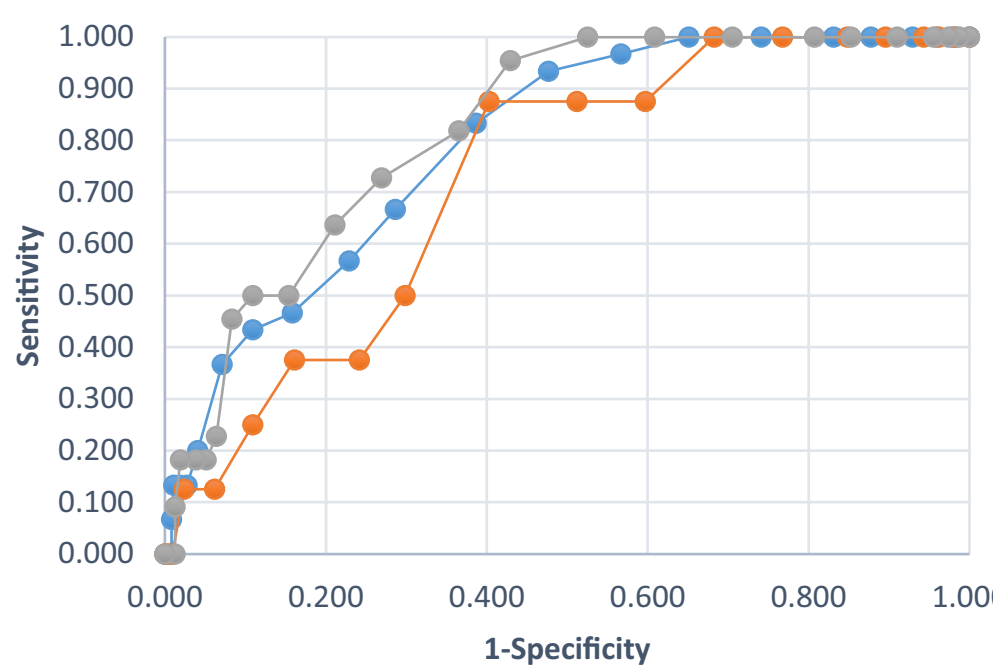

AUC (overall) $=0.795$

$\operatorname{AUC}($ Men $)=0.822$

AUC $($ Women $)=0.725$

Fig. 1 ROC curve for UT2DM for the sample population and by gender 
equal to 11.5 , at which the sensitivity was $83.3 \%$ and specificity was $61.3 \%$ (Table 3 ). Similarly, the optimal cutoff value for women was 11.5 (sensitivity $87.5 \%$; specificity $60 \%$ ) but 10.5 for men (sensitivity $95.5 \%$; specificity $57.1 \%)$.

\section{Diagnostic accuracy for prediabetes}

The AUROC curve for detecting prediabetes was 0.621 (95\% CI: 0.557-0.684) overall, with 0.648 (0.563-0.734) for men better than, $0.59 \sim 0.6(0.492-0.687)$ for women (Fig. 2). The correspondent optimal cutoff point was

Table 3 FINDRISC threshold values for detecting UT2DM, prediabetes and MS according to sensitivity and specificity

\begin{tabular}{lll}
\hline Cutoff points & Sensitivity (\%) & Specificity (\%) \\
\hline UT2DM & & \\
Cuttoff $=9.5$ & 96.70 & 43.30 \\
Cuttoff $=10.5$ & 93.30 & 52.30 \\
Cuttoff $=11.5$ & 83.30 & 61.30 \\
Prediabetes & & \\
Cuttoff $=9.5$ & 74.70 & 43.10 \\
Cuttoff $=10.5$ & 61.50 & 49.70 \\
Cuttoff $=11.5$ & 57.10 & 61.10 \\
MS & & \\
Cuttoff $=9.5$ & 77.50 & 48.20 \\
Cuttoff $=10.5$ & 69.70 & 56.50 \\
Cuttoff $=11.5$ & 62 & 67.50 \\
\hline
\end{tabular}

a FINDRISC equal to 9.5, at which the sensitivity was $73.6 \%$ and specificity was $43.1 \%$ (Table 3 ). Similarly, the optimal cut-off value for both men and women was 9.5 with (sensitivity $77.4 \%$; specificity $48 \%$ ) for men and (sensitivity $71.1 \%$; specificity $39.8 \%$ ) for women.

\section{Diagnostic accuracy for MS}

The AUROC curve for detecting MS was 0.71 (95\% CI: 0.657-0.762) overall, with 0.734 (0.661-0.807) for men slightly better than, 0.705 (95\% CI: 0.626-0.784) for women (Fig. 3). The correspondent optimal cutoff point was a FINDRISC equal to 10.5 , at which the sensitivity was $69.7 \%$ and specificity was $56.5 \%$ (Table 3 ). Similarly, the optimal cut-off value for men was 9.5 (sensitivity $77.6 \%$; specificity $57 \%$ ) while it was 10.5 for women (sensitivity $70.2 \%$; specificity $53.1 \%$ ).

\section{Characteristics of the participants according to FINDRISC categories}

The highest prevalence of most participants characteristics fall in the highest FINDRISC category $>20$, with a remarkable statistical significance, which are WC $112.5( \pm 10.4 ; P<0.001)$, BMI $32( \pm 5.2 ; P<0.001)$, FBG $110.2( \pm 27 ; \mathrm{P}=0.036)$, OGTT $170.6( \pm 79.8$; $\mathrm{P}<0.001)$, TG $227( \pm 154.2 ; \mathrm{P}=0.003)$, HDL-C 35.2 $( \pm 7.1, \mathrm{P}=0.005)$, SBP $138.2( \pm 13.2 ; \mathrm{P}<0.001)$ and, DBP $88.2( \pm 14.8 ; \mathrm{P}=0.038)$. Subjects with a FINDRISC category of 15-20 had the highest prevalence of history of elevated blood glucose 22 (52.4\%; $\mathrm{P}<0.001)$,

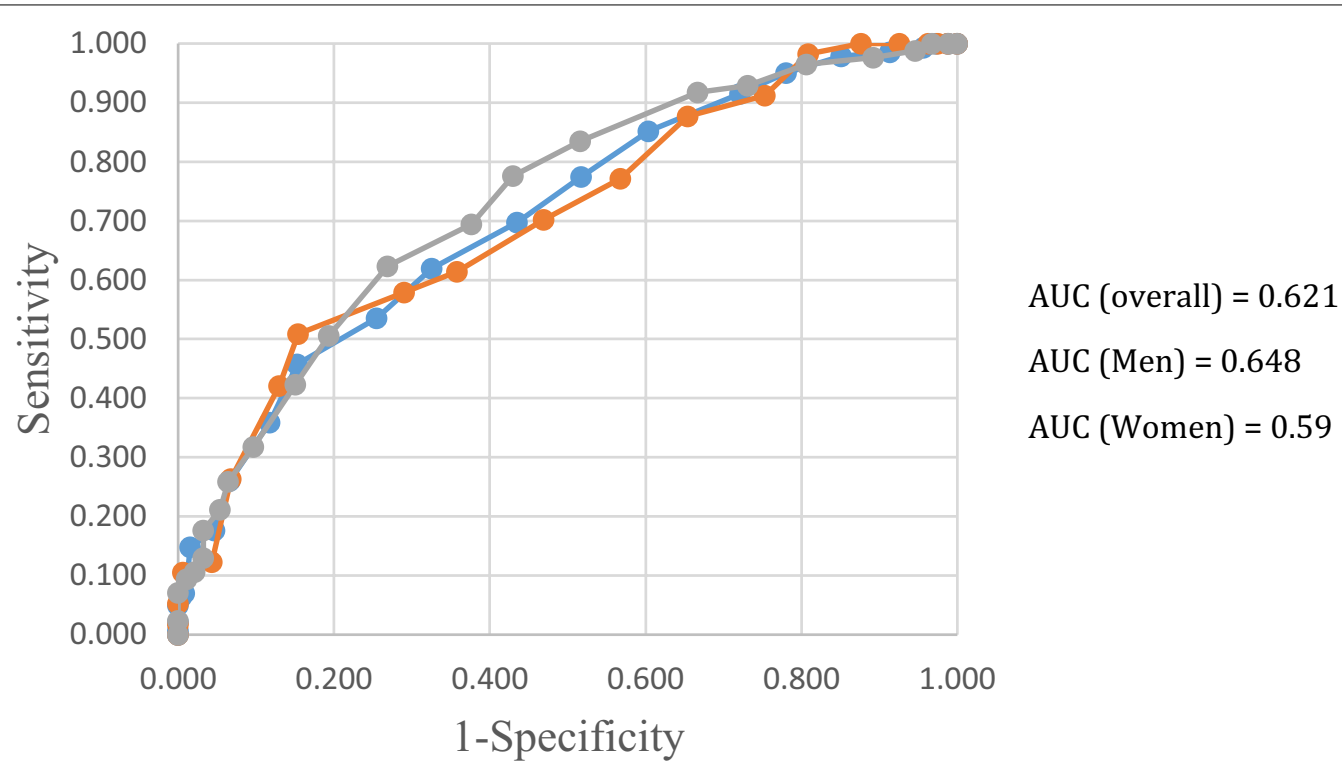

-SAMPLE POPULATION - FEMALE - MALE

Fig. 2 ROC curve for prediabetes for the sample population and by gender 


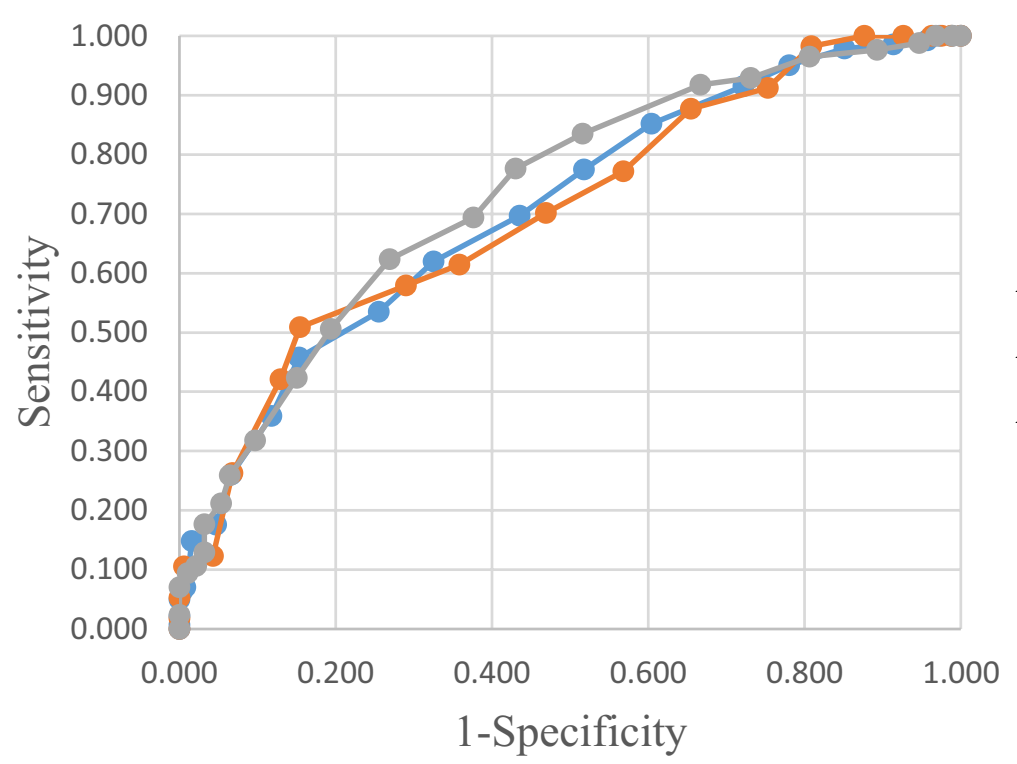

AUC (overall) $=0.71$

$\operatorname{AUC}($ Men) $=0.734$

AUC (Women) $=0.705$

$\longrightarrow$-SAMPLE POPULATION - FEMALE - - MALE

Fig. 3 ROC curve for MS for the sample population and by gender

UT2DM 11 (36.7\%; $\mathrm{P}<0.001)$ and, TC 14 (46.7\%; $P<0.001=0.645)$. Older individuals $51.4 \quad( \pm 8.6$; $\mathrm{P}<0.001)$, current smokers $35(22.6 \%$; $\mathrm{P}=0.522)$ and, those with elevated blood LDL-C levels 126.8 ( \pm 38.1 ; $\mathrm{P}=0.247$ ) are located within a FINDRISC category of 12-14, with a statistical significant except for smokers.
Those with prediabetes 33 (36.3\%; $\mathrm{P}=0.01)$ and MS 51 $(34.5 \% ; \mathrm{P}<0.001)$ had a FINDRISC category of $7-11$ (Table 4).

Table 4 Characteristics of the participants according to FINDRISC categories

\begin{tabular}{|c|c|c|c|c|c|c|}
\hline & \multicolumn{5}{|c|}{ FINDRISC categories } & \multirow[t]{2}{*}{$P$} \\
\hline & $<7$ & $7-11$ & $12-14$ & $15-20$ & $>20$ & \\
\hline Age (in years) & $42.9( \pm 9.08)$ & $47.6( \pm 8.2)$ & $51.4( \pm 8.6)$ & $51.3( \pm 8.3)$ & $50.1( \pm 10.2)$ & $0.000^{*}$ \\
\hline WC (in cm) & $84.2( \pm 11.3)$ & $94.2( \pm 12.2)$ & $98.8( \pm 12.61)$ & $105( \pm 14.7)$ & $112.5( \pm 10.4)$ & $0.000^{*}$ \\
\hline BMI (in kg/m²) & $23.4( \pm 2.36)$ & $26.4( \pm 3.8)$ & $28.3( \pm 4.6)$ & $30.7( \pm 4.87)$ & $32.5( \pm 5.2)$ & $0.000^{*}$ \\
\hline Hx of high BG & $0(0.0 \%)$ & $3(7.1 \%)$ & $7(16.7 \%)$ & $22(52.4 \%)$ & $10(23.8 \%)$ & $0.000^{*}$ \\
\hline Current smoking & $26(16.8 \%)$ & $59(38.1 \%)$ & $35(22.6 \%)$ & $28(18.1 \%)$ & $7(4.5 \%)$ & 0.522 \\
\hline UT2DM & $0(0.0 \%)$ & $6(20.0 \%)$ & $9(30.0 \%)$ & $11(36.7 \%)$ & $4(13.3 \%)$ & $0.000^{*}$ \\
\hline Prediabetes & $6(6.6 \%)$ & $33(36.3 \%)$ & $27(29.7 \%)$ & $23(25.3 \%)$ & $2(2.2 \%)$ & $0.01^{*}$ \\
\hline MS & $8(5.4 \%)$ & $51(34.5 \%)$ & $38(25.7 \%)$ & $42(28.4 \%)$ & $9(6.1 \%)$ & $0.000^{*}$ \\
\hline FBG (in mg/dl) & $88.6( \pm 8.3)$ & $95( \pm 35.7)$ & $97.4( \pm 22)$ & $103( \pm 36.4)$ & $110.2( \pm 27)$ & $0.036^{*}$ \\
\hline 2 h OGTT (in mg/dl) & $89.1( \pm 23.5)$ & $105( \pm 63.6)$ & $117.6( \pm 59.7)$ & $128( \pm 84.6)$ & $170.6( \pm 79.8)$ & $0.000^{*}$ \\
\hline $\mathrm{TC}$ (in $\mathrm{mg} / \mathrm{dl}$ ) & $197( \pm 42.1)$ & $197( \pm 40.3)$ & $198.9( \pm 43)$ & $201( \pm 41.3)$ & $180.2( \pm 35.2)$ & 0.635 \\
\hline TG (in mg/dl) & $121( \pm 62.9)$ & $133( \pm 76)$ & $146( \pm 105.5)$ & $151( \pm 88.6)$ & $227( \pm 154.2)$ & $0.003^{*}$ \\
\hline $\mathrm{HDL}-\mathrm{C}$ (in mg/dl) & $51.9( \pm 14.6)$ & $48( \pm 12.5)$ & $46.7( \pm 14)$ & $48( \pm 14.2)$ & $35.2( \pm 7.1)$ & $0.005^{*}$ \\
\hline LDL-C (in mg/dl) & $120( \pm 37.4)$ & $122( \pm 35.7)$ & $126.8( \pm 38.1)$ & $126( \pm 37.6)$ & $99.7( \pm 33.5)$ & $0.247^{*}$ \\
\hline SBP (in $\mathrm{mmHg}$ ) & $114( \pm 19.3)$ & $118( \pm 24.8)$ & $121.2( \pm 23.6)$ & $130( \pm 20.6)$ & $138.2( \pm 13.2)$ & $0.000^{*}$ \\
\hline $\mathrm{DBP}($ in $\mathrm{mmHg}$ ) & $75( \pm 12.9)$ & $76( \pm 16.3)$ & $78.6( \pm 15)$ & $80( \pm 14.3)$ & $88.2( \pm 14.8)$ & $0.038^{*}$ \\
\hline
\end{tabular}




\section{Discussion}

\section{Key findings}

In this cross-sectional study, FINDRISC had a good performance in identifying UT2DM and MS in the working population (Office workers, instructors, and cleaners) of the LU Campuses, but a poor performance regarding prediabetes.

\section{Comparison with other studies Prevalence of UT2DM, prediabetes, and MS}

The prevalence of UT2DM and prediabetes in our study was $7.6 \%$ and $22.9 \%$ respectively. However, a recent study carried out in the Bekaa, which is a rural area in Lebanon [26] found that the estimates of diabetes and prediabetes were $26 \%$ and $8.5 \%$ respectively using a sample of 200 individuals. Nevertheless, the prevalence of diabetes and prediabetes was reported to be $15 \%$ and $40.3 \%$ respectively in the Greater Beirut Area in a sample of 501 people [9]. These findings indicate that the prevalence of both diabetes and prediabetes are high in different Lebanese settings. As for MS prevalence, it was estimated to be $36 \%$ among LU employees. Similarly, a recent cross-sectional study has been carried out in Notre Dame University employees on the three campuses (Zouk Mosbeh, North and Al Chouf) and found that $23.5 \%$ of the participants were suffering from MS [27]. These findings are alarming, suggesting that LU employees are, in general, unaware of their health status which is highlighted by a low percent of physical activity practice (85\%) [28], high waist circumference especially for men $(102.8 \pm 12.1 \mathrm{~cm})$ [29] and an overweight population [30]. These factors have been largely discussed and identified as risk factors for diabetes and 'metabolic syndrome' and associated health problems. Thus, the importance of the FINDRISC use among them is highlighted.

\section{Performance of FINDRISC in detecting UT2DM, prediabetes and MS}

Originally, the FINDRISC questionnaire was developed longitudinally as a future predictor of diabetes in the Finnish population [20] and was validated from a multivariate logistic regression model five years later. It was subsequently cross-sectionally validated using a maximum score of 26 [31]. Later on, it has been assessed in a cross-sectional manner in several Asian [32-34], European [35-42], and American countries [43-45]. In these studies, the optimal cut-off points for detecting UT2DM varied widely from 8.5 to 17 with a sensitivity ranging from 48 to $84 \%$ and a specificity ranging from $30.9 \%$ to $95 \%$. Also, the AUROC went from 0.569 to 0.88 . This vast variability indicates the need for assessing the tool within its target population.

In this study, FINDRISC had a good discriminative ability for detecting UT2DM with an AUROC value of 0.795 (0.822 in men; 0.725 in women) and a threshold value of 11.5 (10.5 in men; 11.5 in women). Besides, it's also good at detecting MS in both men and women with an AUROC of 0.7 (0.713 in men; 0.708 in women) at a threshold of 10.5 (9.5 in men; 10.5 in women). Whereas, this ability gets weaker in case of prediabetes as evidenced by an AUROC of 0.621 (0.648 in men; 0.59 in women) especially in women. Several studies showed similar values and also confirmed that FINDRISC performed better in detecting UT2DM and MS than prediabetes. In a previous cross-sectional study on the general population of the United States of America [45], the AUROC for UT2DM was 0.75 (0.74 in men; 0.78 in women) with an optimal cutoff value of 11 in men and 12 in women, while the AUROC for prediabetes was 0.67 (0.66 in men; 0.7 in women) with an optimal cutoff of 9 in men and 10 in women. Likewise, in the Philippines [32], FINDRISC was good at predicting T2DM with an AUROC of 0.738 (0.749 in men; 0.734 in women) but failed to screen for prediabetes $(A U R O C=0.562)$. Similar trends were noticed in the original FINDRISC study regarding the performance of the tool in detecting the three outcomes [31]. In other words, the AUROC for MS discrimination was 0.72 in men and 0.75 in women. However, the optimal cutoff values for detecting T2DM and prediabetes were both 11 with lower sensitivities and specificities than the ones found in this study, and the optimum cutoff for MS was not established. Similarly, FINDRISC was also found to perform well in the detection of MS (AUC $=0.77$ ) in Taiwanese [46], but the optimal cutoff point was not reported. One previous cross-sectional study in Greece [35] reported a threshold for MS of 15 which is higher than the one reported in our study. However, it is well known that prediabetes which is a combination of excess body fat and insulin resistance, is considered an underlying etiology of MS [47]. In turns, MS is considered as a risk factor for T2DM [48] which may explain why $70 \%$ of people with prediabetes in this study had MS $(P<0.0001)$ and $76 \%$ of those with UT2DM had MS and that's why the threshold for MS is localized between the thresholds for prediabetes and UT2DM in our community. To date, only one study assessed the predictive ability of FINDRISC in detecting incident cases of MS (AUC $=0.65$ ) rather than prevalent cases at a cutoff of 12 [49].

It is also worth mentioning that men had always higher AUROC values as well as lower cutoff values than women, specifically for UT2DM and MS in the current study. In other words, men tend to have more risk factors 
putting them at a higher risk for diabetes, prediabetes, and MS which improves the predictive ability of FINDRISC when compared with women and increases their scoring in FINDRISC and thus limiting their threshold to lower values. In this study, a synergistic interaction for the combined BMI $(\mathrm{p}<0.0001)$, WC $(\mathrm{p}<0.0001)$, smoking $(\mathrm{p}<0.0001)$, could renders men more prone for diabetes with higher prevalence for UT2DM $(p=0.001)$ and MS $(\mathrm{p}<0.0001)$.

\section{The usefulness of FINDRISC as a screening tool among $L U$ workers}

The advantage of the FINDRISC relies on its selfreport questions so that $\mathrm{LU}$ workers that reported to be extremely busy because of their work and daily life stressors can find it easier to fill the FINDRISC quickly and rate their current health status. Being at higher risk based on FINDRIC score would be a sufficient trigger for them to start applying lifestyle changes or to seek health professionals' help.

\section{Strengths and limitations of the study}

Some limitations warrant considerations. First, a misclassification bias could be introduced because the diagnosis of diabetes of the respondents was self-reported. Further, the diagnosis of diabetes and prediabetes of the included participants was not confirmed by repeat testing on a separate day as recommended [14]. However, these tests may pose additional costs on our limited budget. Second, a selection bias could be present as the participants were drawn only from LU campuses and, thus, the results may not be generalizable to the rest of the Lebanese citizens living in other settings. Third, we could not assess the ability of the FINDRISC to catch the future risk of having diabetes and MS as it was tested in some longitudinal studies [49-51].

This study has also considerable strengths. To our knowledge, this is the second study that has been carried out in an Arabic country in the Middle East region which has investigated the validity of FINDRISC. A previous study was conducted in Kuwait and showed similar results [33]. Additionally, a recent Jordanian study pointed out the usefulness of FINDRISC to screen for type 2 diabetes in a young student population but didn't have the opportunity to validate it [52]. Second, a selection bias was avoided since our sample was fairly divided between men (44.8\%) and women (50.2\%) and thus the gender differences in the study outputs are not biased. Third, the diagnosis of diabetes was done based on a combination of two plasmatic tests as it is ideally recommended which are the FBG and OGTT. Thus, the misclassification bias would be lessened, and the estimation of the risk of T2DM as well as the performance of FINDRISC are optimized.

\section{Conclusion and perspectives}

This cross-sectional study has successfully demonstrated that FINDRISC could be useful as a first-line screening tool that identifies employees with UT2DM, prediabetes, and MS that might benefit from lifestyle modification. FINDRISC model could be also beneficial for community-based interventions and screenings as well as in clinical practice by the health professionals. In future studies, FINDRISC should be validated on a larger and more representative sample of the Lebanese population so Lebanese citizens living in a resource-poor setting like rural areas would benefit the most. Also, FINDRISC should be assessed in a longitudinal study who allows the identification of incident cases of diabetes and MS rather than prevalent cases.

\section{Acknowledgements \\ The authors are grateful to all individuals who kindly agreed to participate in this study as well as for each center in which blood tests were analyzed.}

\section{Authors' contributions}

MA, MH and ZD conceived and designed the study; MA, SS, MH, MS, TF, and ZM contributed to data collection; MA, SS and MS analyzed the data; SS and MS wrote the paper; MA, MH and ZM reviewed the article. All authors read and approved the final manuscript.

\section{Funding}

This work was funded by the Lebanese University.

Availability of data and materials

Not applicable.

\section{Ethics approval and consent to participate}

This work was pertinent to the Declaration of Helsinki. The informed consent and questionnaire were approved by the Ethical Institutional Committee at Ain w Zein hospital in Al Chouf, Mount Lebanon. Anonymity was respected for all participants, with a numerical annotation attributed to each questionnaire and blood tube samples.

\section{Consent for publication}

Not applicable.

\section{Competing interests}

The authors declare that they have no competing interests.

\section{Author details \\ ${ }^{1}$ Faculty of Public Health, Lebanese University, Hadat, Beirut, Lebanon. ${ }^{2}$ Department of Nutrition and Dietetics, Faculty of Public Health, Lebanese University, Hadat, Beirut, Lebanon. ${ }^{3}$ Medical Laboratory, Lebanese Univer- sity Medical Center, Lebanese University, Hadat, Beirut, Lebanon. ${ }^{4}$ Sciences Department, Faculty of Public Health, Lebanese University Hadat, Hadat, Beirut, Lebanon.}

Received: 24 July 2020 Accepted: 19 September 2020

Published online: 30 September 2020

References

1. Goyal R, Jialal I. Diabetes Mellitus Type 2. Treasure Island (FL): StatPearls Publishing; 2019. 
2. Tabák AG, Herder C, Rathmann W, Brunner EJ, Kivimäki M. Prediabetes: a high-risk state for diabetes development. Lancet. 2012:379(9833):2279-90.

3. Olokoba AB, Obateru OA, Olokoba LB. Type 2 Diabetes diabetes mellitus: a review of current trends. Oman Med J. 2012;27(3):269-73.

4. Roberts CK, Hevener AL, Barnard RJ. metabolic syndrome and insulin resistance: underlying causes and modification by exercise training. Compr Physiol. 2013;3:1-58.

5. Centers for Disease Control and Prevention. National Diabetes Statistics Report. U.S. Dept of Health and Human Services; 2017 p. 20.

6. Saklayen MG. The global epidemic of the metabolic syndrome. Curr Hypertens Rep. 2018;20(2):12

7. International Diabetes Federation. Global Guideline for Type 2 Diabetes, Clinical guidelines task force, 2012.

8. World Health Organization, Lebanon. 2016. https://www.who.int/diabe tes/country-profiles/lbn_en.pdf?ua =1

9. Nasrallah MP, Nakhoul NF, Nasreddine L, Mouneimne Y, Abiad MG, Tamim $H$. Prevalence of diabetes in Greater Beirut area: Worsening over time. Endocr Pract. 2017;23:1091-100.

10. Costanian C, Bennett K, Hwalla N, Assaad S, Sibai AM. Prevalence, correlates and management of type 2 diabetes mellitus in Lebanon: Findings from a national population-based study. Diabetes Res Clin Pract. 2014;105:408-15.

11. Ghassibe-Sabbagh M, Deeb M, Salloum AK, Mouzaya F, Haber M, Al-Sarraj Y, Chami Y, Akle Y, Hirbli K, Nemr R, Ahdab R, Platt DE, Abchee $A B$, El-Shanti H, Alloua AP. Multivariate epidemiologic analysis of type 2 diabetes mellitus risks in the Lebanese population. Diabetol Metab Syndr. 2014;1(6):89.

12. Ansarimoghaddam $A$, Adineh $H A$, Iraj Z, Sohrab I, HosseinZadeh A, Ali H. Prevalence of metabolic syndrome in Middle-East countries: Meta-analysis of cross-sectional studies. Diabetes Metab Syndr. 2018;12(2):195-201.

13. Zhang P, Gregg E. Global economic burden of diabetes and its implications. Lancet Diabetes Endocrinol. 2017:5:404-5.

14. American Diabetes Association. Classification and Diagnosis of Diabetes: Standards of Medical Care in Diabetes_2018. Diabetes Care. 2018;41(Suppl 1):13-27.

15. Buijsse B, Simmons RK, Griffin SJ, Schulze MB. Risk Assessment Tools for Identifying Individuals at Risk of Developing Type 2 Diabetes. Epidemiol Rev. 2011;33:46-62.

16. Bang $H$, Edwards AM, Bomback AS, Ballantyne CM, Brillon D, Callahan MA, Teutsch SM, Mushlin Al, Kern LM. Development and validation of a patient self-assessment score for diabetes risk. Ann Intern Med. 2009;151:775-83.

17. Schulze MB, Hoffmann K, Boeing H, Linseisen J, Rohrmann S, Möhlig M, Pfeiffer AFH, Spranger J, Thamer C, Häring HU, Fritsche A, Joost HG. An Accurate Risk Score Based on Anthropometric, Dietary, and Lifestyle Factors to Predict the Development of Type 2 Diabetes. Diabetes Care. 2007;30(1):510-5.

18. Brown N, Critchley J, Bogowicz P, Mayige M, Unwin N. Risk scores based on self-reported or available clinical data to detect undiagnosed Type 2 Diabetes: a systematic review. Diabetes Res Clin Pract. 2012;98(3):369-85.

19. Noble D, Mathur R, Dent T, Meads C, Greenhalgh T. Risk models and scores for type 2 diabetes: systematic review. BMJ. 2011;343:d7163.

20. Lindstrom J, Tuomilehto J. The Diabetes Risk Score: A practical tool to predict type 2 diabetes risk. Diabetes Care. 2003;26(3):725-31.

21. Centers for Disease Control and Prevention. Anthropometry Procedures Manual. 2017.https://www.cdc.gov/NCHS/data/nhanes/nhanes_07_08/ manual_an.pdf.

22. Centers for Disease Control and Prevention. Body Mass Index (BMI). 2018: https://www.cdc.gov/healthyweight/assessing/bmi/childrens_bmi/child rens_bmi_formula.html

23. Muntner P, Shimbo D, Carey RM, Charleston JB, Gaillard T, Misra S, Myers MG, Ogedegbe G, Schwartz JE, Townsend RR, Urbina EM, Viera AJ, White WB, Wright JT Jr. Measurement of Blood Pressure in Humans: A Scientific Statement from the American Heart Association. Hypertension. 2019:73(5):35-66

24. Friedewald WT, Levy RI, Fredrickson DS. Estimation of the concentration of low-density lipoprotein cholesterol in plasma, without use of the preparative ultracentrifuge. Clin Chem. 1972;18(6):499-50225.

25. Huang PL. A comprehensive definition for metabolic syndrome. Dis Model Mech. 2009:2(5-6):231-7.
26. Mortada D, Wehbe T, Abou JE. Prevalence of diabetes and pre-diabetes in a cohort of high risk undiagnosed patients. Int J Food Sci Nutr Diet. 2018:7(1):372-6.

27. Ghadieh R, Mosleh J, Al Hayek S, Merhi S, El-Hayek FJ. The relationship between hypovitaminosis $\mathrm{D}$ and metabolic syndrome: a cross sectional study among employees of a private university in Lebanon. BMC Nutr. 2018;4:36.

28. Colberg SR, Sigal RJ, Yardley JE, Riddell MC, Dunstan DW, Dempsey PC, Horton ES, Castorino K, Tate DF. Physical Activity/Exercise and Diabetes: A Position Statement of the American Diabetes Association. Diabetes Care. 2016;39(11):2065-79.

29. Siren R, Eriksson JG, Vanhanen $\mathrm{H}$. Waist circumference a good indicator of future risk for type 2 diabetes and cardiovascular disease. BMC Public Health. 2012;12:631.

30. Saaristo T, Peltonen M, Lindström J, Saarikoski L, Sundvall J, Eriksson JG, Tuomilehto J. Cross-sectional evaluation of the Finnish Diabetes Risk Score: a tool to identify undetected type 2 diabetes, abnormal glucose tolerance and metabolic syndrome. Diabetes Vasc Dis Res. 2005;2(2):67-72.

31. Vazquez G, Duval S, Jacobs DR, Silventoinen K. Comparison of body mass index, waist circumference, and waist/hip ratio in predicting incident diabetes: a meta-analysis. Epidemiol Rev. 2007;29:115-28.

32. Ku GMV, Kegels G. The performance of the Finnish Diabetes Risk Score, a modified Finnish Diabetes Risk Score and a simplified Finnish Diabetes Risk Score in community-based cross-sectional screening of undiagnosed type 2 diabetes in the Philippines. Prim Care Diab. 2013;7(4):249-59.

33. Al Khalaf MM, Eid MM, Najjar HA, Alhajry KM, Doi SA, Thalib L. screening for diabetes in Kuwait and evaluation of risk scores. East Mediterr Health J. 2010;16(7):725-31.

34. Gao WG, Dong YH, Pang ZC, Nan HR, Wang SJ, Ren J, Zhang L, Tuomilehto J, Qiao Q. simple Chinese risk score for undiagnosed diabetes. Diabet Med. 2010;27(3):274-81.

35. Makrilakis K, Liatis S, Grammatikou S, Perrea D, Stathi C, Tsiligros P, Katsilambros N. Validation of the Finnish diabetes risk score (FINDRISC) questionnaire for screening for undiagnosed type 2 diabetes, dysglycaemia and the metabolic syndrome in Greece. Diabetes Metab. 2011;37(2):144-51.

36. Silvestre MP, Jiangc $Y$, Volkova $K$, Chisholma $H$, Wonjoo Lee W, Poppitt SD. Evaluating FINDRISC as a screening tool for type 2 diabetes among overweight adults in the PREVIEW:NZ cohort. Prim Care Diab. 2017;11(6):561-9.

37. Vandersmissen G, Godderis L. Evaluation of the Finnish Diabetes Risk Score (FINDRISC) for diabetes screening in occupational health care. Int J Occup Med Environ Health. 2015;28(3):587-91.

38. Tankova T, Chakarova N, Atanassova I, Dakovska L. Evaluation of the Finnish Diabetes Risk Score as a screening tool for impaired fasting glucose, impaired glucose tolerance and undetected diabetes. Diabetes Res Clin Pract. 2011;92(1):46-52.

39. Štiglic G, Fijačko N, Stožer A, Sheikh A, Pajnkihar M. Validation of the Finnish Diabetes Risk Score (FINDRISC) questionnaire for undiagnosed type 2 diabetes screening in the Slovenian working population. Diabetes Res Clin Pract. 2016;120:194-7.

40. Witte DR, Shipley MJ, Marmot MG, Brunner EJ. Performance of existing risk scores in screening for undiagnosed diabetes: an external validation study: performance of diabetes risk scores. Diabet Med. 2010;27(7):46-53.

41. Rathmann W, Martin S, Haastert B, Icks A, Holle R, Löwel H, Giani G. Performance of Screening Questionnaires and Risk Scores for Undiagnosed Diabetes: The KORA Survey 2000. Arch Intern Med. 2005;165:436.

42. Franciosi M, Berardis GD, Rossi MCE, Sacco M, Belfiglio M, Pellegrini F, Tognoni G, Valentini M, Nicolucci A. Use of the Diabetes Risk Score for Opportunistic Screening of Undiagnosed Diabetes and Impaired Glucose Tolerance: The IGLOO (Impaired Glucose Tolerance and Long-Term Outcomes Observational) study. Diabetes Care. 2005;28(5):1187-94.

43. Bernabe-Ortiz A, Perel P, Miranda JJ, Smeeth L. Diagnostic accuracy of the Finnish Diabetes Risk Score (FINDRISC) for undiagnosed T2DM in Peruvian population. Prim Care Diab. 2018;12(6):517-25.

44. Gomez-Arbelaez D, Alvarado-Jurado L, Ayala-Castillo M, Forero-Naranjo L, Camacho PA, Patricio L-J. Evaluation of the Finnish Diabetes Risk Score to predict type 2 diabetes mellitus in a Colombian population: A longitudinal observational study. World J Diabetes. 2015;6(17):1337-444. 
45. Zhang L, Zhang Z, Zhang Y, Hu G, Chen L. Evaluation of finnish diabetes risk score in screening undiagnosed diabetes and prediabetes among U.S. adults by gender and race: NHANES 1999-2010. PLOS ONE. 2014;9(5):e97865.

46. Lin J-W, Chang YC, Li HY, Chien YF, Wu MY, Tsai RY, Hsieh YC, Chen YJ, Hwang JJ, Chuang LM. Cross-sectional validation of diabetes risk scores for predicting diabetes, metabolic syndrome, and chronic kidney Disease in Taiwanese. Diabetes Care. 2009;32(12):2294-6.

47. Grundy SM. Pre-Diabetes, Metabolic Syndrome, and Cardiovascular Risk. J Am Coll Cardiol. 2012;59(7):635-43.

48. Shin J, Lee JH, Lim SY, Ha HS, Kwon HS, Park YM, Lee WC, Kang MI, Yim $\mathrm{HW}$, Yoon KH, Son HY. Metabolic syndrome as a predictor of type 2 diabetes, and its clinical interpretations and usefulness. J Diabetes Investig. 2013;4(4):334-43.

49. Janghorbani $M$, Adineh $H$, Amini M. Evaluation of the Finnish Diabetes Risk Score (FINDRISC) as a Screening Tool for the Metabolic Syndrome. Rev Diabet Stud. 2013;10(4):283-92.
50. Zhang $M$, Zhang H, Wang $C$, Ren $Y$, Wang B, Zhang L, Yang $X$, Zhao Y, Han C, Pang C, Yin L, Xue Y, Zhao J, Hu D. Development and validation of a risk-score model for type 2 diabetes: a cohort study of a rural adult chinese population. PLoS ONE. 2016;11(4):e0152054.

51. Janghorbani M, Adineh H, Amini M. Finnish Diabetes Risk Score to predict type 2 diabetes in the Isfahan diabetes prevention study. Diabetes Res Clin Pract. 2013;102(3):202-9.

52. Al-Shudifat A-E, et al. Diabetes risk score in a young student population in Jordan: a cross-sectional study. J Diabetes Res. 2017;2017:1-5.

\section{Publisher's Note}

Springer Nature remains neutral with regard to jurisdictional claims in published maps and institutional affiliations.
Ready to submit your research? Choose BMC and benefit from:

- fast, convenient online submission

- thorough peer review by experienced researchers in your field

- rapid publication on acceptance

- support for research data, including large and complex data types

- gold Open Access which fosters wider collaboration and increased citations

- maximum visibility for your research: over $100 \mathrm{M}$ website views per year

At BMC, research is always in progress.

Learn more biomedcentral.com/submissions 